\title{
Research on Application of Information Management and Management Science in Economic Activities
}

\author{
Songwen Fang ${ }^{1}$ \\ ${ }^{1}$ Tianjin University, Tianjin, 300072
}

\begin{abstract}
Keywords: Application, Information Management, Management Science, Economic Activities
\end{abstract}
\begin{abstract}
Information management science is a multidisciplinary scientific achievement of related disciplines. Information science, sociology, management science, information theory, systems theory, and cybernetics provide the scientific basis for it. Its historical mission is to provide theoretical and technical support and guarantees for social informationization. Its intrinsic relations with various related disciplines and structural relationships determine its position in the human science system. Information management science is a highly integrated cross-discipline. In the framework of social management, the construction of a complete scientific system consisting of three aspects of basics, applications, and engineering technologies to adapt to the needs of social development is the direction of its discipline construction.
\end{abstract}

\section{Introduction}

In the 1940s, the development of modern information technology represented by electronic computer technology set off a wave of information revolution and initiated the informationization process of human society. With the deepening of the information revolution and the universal application of modern information technology in all fields of society, the human society has been accelerating its informatization process. What is happening synchronously with this process is the transformation of human society in the field of social resources-the first qualitative leap and sublimation of the basic resources in which human society depends on for survival and development-from material resources to non-material resources. On this basis, since the middle and late 20th century, especially since the 1970s and 1980s, Western developed countries have entered the era of information economy. Correspondingly, the management of information resources, the basic resource of the information economy, has become a very real problem in these countries. The United States first proposed the idea of information management in the 1980s. The deepening of information resource management practices and information management ideas in developed countries has initiated the globalization of the world economy. This process is the realization process of the human society informatization in the economic field. The realistic basis of global economic globalization is the scientific management and effective development of social information resources with the support of modern information technology. In terms of its sociological significance, the process of economic globalization in today's world is an integral part of the complete process of informationization of human society, specifically its basic structure. The informatization process of human society will be a quite long historical period. At present, it is only the beginning of this historical stage. In the initial stage of the informatization process of human society, the informatization of the world economy with economic globalization as its form is the main body of social informatization. World economic informatization not only means that the information economy that has already been realized in several developed countries will expand and deepen on a global scale. It also means that modern information technology and corresponding social facilities are rapidly becoming the technological foundation of the entire economic field, and more important the significance is that information resources will quickly become a strategic basic resource for the development of human society. In this way, the ability to scientifically manage and effectively develop social information resources will become the ultimate indicator of the overall national strength of a country. The field of information resource management is bound to become the commanding heights and hotspots of international competition in the 21st century. Under this 
circumstance, under the impetus of the theoretical research of information management and the social practice of information management, a brand-new discipline, Information Management Science, was born.

\section{The Scientific Basis and Historical Mission of Information Management Science}

In the history of the development of human sciences, the emergence, formation, and development of any science are not groundless, and are not the result of individual subjective assertions. A profound historical background, a solid scientific foundation, and a clear social task to meet the specific historical needs of human society development are prerequisites for the emergence, formation, and development of a discipline. The disciplines one after another are formed and developed on the basis of these historical conditions, forming a huge, complex and orderly scientific system structure of human society today. The historical background of information management science is described in the preface. This article discusses its scientific foundation and historical mission as follows:

Information management science takes social information, information behavior, information phenomena and social information systems as the research object. Through the research on the laws of social movement of information and information, it studies the organizational management theory and management engineering technology of information work and information industry. Optimize the structure and function of social information systems so as to achieve the rational development and effective use of social information resources, and then promote the social informationization process, and promote a discipline of information economy and overall social development.

Because people and information have a natural connection, so information is one of the elements of the human social system. Information behavior is one of the most basic social behaviors of human and human society. As a result, information, information behavior, and information management practices, as social existence, social behavior, and social phenomena, will inevitably be accompanied by the complete history of human social development. In other words, at the social practice level, human information, information behavior, and information management practices not only have an ancient and long history as human society itself, but also together with the reality of human society and future development, not only have the vitality of reality, but also with continuous development of vitality. However, at the cognitive level, "information management", as a theoretical understanding of human beings, originates from the conception and discussion of related concepts, and the formation of relevant theoretical systems serves as its mature historical symbol. As an applied science, information management science not only needs a basic theoretical system as its theoretical support, but also has its applied theoretical system as the subject of its discipline structure. It also needs a corresponding engineering technology system as its application means and technical support. If such a theory--technical system is not formed, it cannot be a systematic, complete, and mature scientific system that can meet the needs of modern society's information construction. To study the scientific basis of information management science, it is necessary to explore its theoretical basis, technical foundation, and methodological basis for this complete scientific system.

Research objects, theoretical basis and research methods are the basic elements that constitute a discipline. To study the scientific basis of a discipline, it is generally necessary to start with the object of study. Human information, information behavior and information management practices are the research objects of information management science. The industrialized organizational form of contemporary human social information management practices is the information industry. If we say that information itself is the microscopic object of information management, then information behavior and information industry are the macroscopic objects of information management.

At present, the nature of information and the basic definition of the concept of information at the philosophical level in the academic world are still in a situation where there are many opinions. However, this state does not affect the definition of information concepts from the perspective of information management. For information management, information exists not only as a basic 
concept of information science, but more importantly as a constituent element and social resource of human society. For this reason, information has the sociological and managerial implications. The human information behavior and information management practices as human basic social behavior and social phenomena are also in the perspective of sociology and management. In this way, information science, sociology and management science constitute the three scientific foundations of information management science. The basic research and applied research of the three parts respectively form the basic theory and applied theoretical basis of information management science, and the information technology and information engineering part of information science, the social management engineering part of sociology, and the management engineering part of management science, It provides the technical foundation for the information management science information management project. The methodological systems of these three universities constitute the methodological basis of information management science. The dissipative structure theory, catastrophe theory, and synergy theory that were developed during and after the formation and development of information theory, system theory, and control theory had a fundamental impact on information science, sociology, and management science. The latter three disciplines not only used these latest scientific ideas and theoretical results as the theoretical basis for the establishment or transformation of the disciplinary architecture, but also established or updated the methodological system of the discipline. Management engineering, social systems theory, social cybernetics, and social management engineering are the theoretical results of this scientific practice. Therefore, if the theoretical and methodological systems of information science, sociology, and management science are the direct foundations of information management science, then information theory, system theory, and cybernetics, and later dissipative structure theory, catastrophe theory, and coordination theory, it forms the indirect foundation and the fundamental source of the theory and methodology of information management science. Correspondingly, the social information system theory and social information management engineering of human society constitute the basic structure of the discipline system of information management science.

The system constitutes the methodological basis of information management science. The dissipative structure theory, catastrophe theory, and synergy theory that were developed during and after the formation and development of information theory, system theory, and control theory had a fundamental impact on information science, sociology, and management science. The latter three disciplines not only used these latest scientific ideas and theoretical results as the theoretical basis for the establishment or transformation of the disciplinary architecture, but also established or updated the methodological system of the discipline. Management engineering, social systems theory, social cybernetics, and social management engineering are the theoretical results of this scientific practice. Therefore, if the theoretical and methodological systems of information science, sociology, and management science are the direct foundations of information management science, then information theory, system theory, and cybernetics, and later dissipative structure theory, catastrophe theory, and coordination theory, It forms the indirect foundation and the fundamental source of the theory and methodology of information management science. Correspondingly, the social information system theory and social information management engineering of human society constitute the basic structure of the discipline system of information management science.

\section{The Application of Information Management and Management Science in Economic Activities}

At the basic theoretical level, the historical height of the construction of information civilization has made a historical grasp of the civilized nature of contemporary human civilization: the social informationization process of contemporary human society and its essence is the historical construction and formation process of information civilization. Information civilization is a historical civilization created by human society in the information age. This is a kind of newest human civilization. This civilization uses information as the basic mechanism of social contact, modern information technology as the basic means of social development, information economy as the basis, and scientific management and effective use of information resources as its content, 
through the effective development and utilization of information resources. Based on the limited development of material resources and unlimited use at different levels, while achieving the internal coordination and overall progress of human society, the coordinated development of human society and the natural environment is realized, and ultimately the sustainable development of human society is achieved. .

In the history of human civilization, information civilization is both a negation of material civilization and a qualitative leap of human civilization. Under the historical conditions of the material civilization represented by industrial civilization, while enjoying the unprecedentedly prosperous material civilization, mankind has to face the price that must be paid to enjoy this prosperity-human survival represented by environmental deterioration. This crisis has led to unprecedented theoretical puzzles and practical shocks. This confusion and impact directly led to the confusion of human beings about their own future and the confusion of existing value systems. Short-term behavior, quick success, moral loss, and the spread of cult phenomena and doomsday trends throughout the world are the real manifestations of this confusion and confusion. This phenomenon is particularly evident in countries where social development is relatively backward and is more directly affected by the world economy. The construction of information civilization can solve various social contradictions and social crises that cannot be solved due to the inability of material resources to be shared and regenerated, and can achieve social ideals that cannot be achieved under the historical conditions of material civilization. Information civilization shows the dawn of humanity's highest social ideal.

One of the historical missions of information management science is to provide an accurate theoretical grasp of the civilized nature of contemporary human civilization from the historical perspective of information civilization construction. On this basis, it provides basic theoretical guidance for the construction of application theory system of information management science to grasp its construction direction, and makes necessary scientific and social control on the level of humanities construction for the modern application of social information technology so that it cannot have confronting with the essence of information civilization and the humanistic spirit, at the same time, it is fundamental to the development prospects of human civilization. At the same time, it should also be a clear theoretical description.

\section{Conclusion}

Science and technology management is a science and technology based on its own characteristics and laws, the use of modern management science principles, principles and methods, organization and management of scientific and technological undertakings and scientific and technological activities, in order to promote scientific and technological progress to effectively play a scientific and technological social functions. Science and technology information management in the field of science and technology management (its predecessor was science and technology information science) constituted a cross-domain with information management science.

\section{References}

[1] Wang Fusheng, Yang Hongyong. Author's research cooperation network model and empirical research [J]. Library and Information Service. 2007 (10)

[2] Guo Jinli, Wang Lina. A class of scale-free networks with power law exponents between 1 and 3 [J]. Acta Phys. Sin., 2007 (10)

[3] Li Kaixuan, Lin Na, Yang Hongyong. Analysis of author cooperation network model based on Journal of Information Science [J]. Modern Intelligence. 2007 (09)

[4] Huang Ping, Zhang Xujie, Liu Gang. Research Status and Prospect of Small-World Networks [J]. Journal of Information. 2007 (04)

[5] Ouyang Xia. Network Visualization Research of EAMOLA Members' Scientific Research Cooperation Behavior [J]. Library and Information Knowledge. 2006 (06) 